\title{
IRS-2 rs1805097 polymorphism is associated with the decreased risk of colorectal cancer
}

\author{
Jiefeng Yin ${ }^{1}$, Zhe Zhang ${ }^{1}$, Huajun Zheng ${ }^{2}$, Lei $\mathbf{X u}^{2}$ \\ ${ }^{1}$ General Surgery Department, Tongde Hospital of Zhejiang Province, Hangzhou, Zhejiang, China \\ ${ }^{2}$ Department of Digestion, The Second Affiliated Hospital of Zhejiang Chinese Medical University, Hangzhou, Zhejiang, China \\ Correspondence to: Lei $X U$, email: leixu123123@163.com \\ Keywords: IRS-2, single nucleotide polymorphism, colorectal cancer, meta-analysis, rs 1805097 \\ Received: November 14, 2016 \\ Accepted: January 27, 2017 \\ Published: February 15, 2017 \\ Copyright: Yin et al. This is an open-access article distributed under the terms of the Creative Commons Attribution License \\ (CC-BY), which permits unrestricted use, distribution, and reproduction in any medium, provided the original author and source \\ are credited.
}

\section{ABSTRACT}

Recent studies explored the association between insulin receptor substrate-2 (IRS-2) gene rs1805097 polymorphism and colorectal cancer (CRC) with contradictory findings. Therefore, we conducted a comprehensive meta-analysis by searching the databases of PubMed and Embase. Pooled odds ratios (ORs) and 95\% confidence intervals (CIs) were calculated by using fixed-effect or random-effect models. A total of 5 citations containing 6 case-control studies involving 4,333 cases and 5,333 controls were included. Our data indicated that IRS-2 rs1805097 polymorphism was associated with decreased risk of CRC. Stratification analysis of ethnicity found that rs1805097 polymorphism decreased the risk of CRC among Americans. Stratification analysis of cancer type suggested that this polymorphism decreased the risk of colon cancer. In summary, this meta-analysis indicates that IRS-2 gene rs1805097 polymorphism plays an important role in the pathogenesis of CRC.

\section{INTRODUCTION}

Colorectal cancer (CRC) is the second most commonly diagnosed cancer worldwide [1]. CRC is one of the primary causes of cancer-related mortality. To date, the etiology of $\mathrm{CRC}$ is still unclear. Some environmental factors including diet, cigarette smoking, physical inactivity, and alcohol consumption, are considered to influence the risk of CRC [2]. Studies demonstrated that those environmental factors through the insulin pathway are significantly associated with the risk of CRC [3, 4]. Several researches provided evidence to support that insulin is associated with the risk of CRC [3, 4]. Some researchers reported that hyperinsulinaemia and type 2 diabetes influence the risk of colon cancer [5]. Animal research found that insulin enhances the growth of aberrant crypt foci, CRC precursor lesions, and increases the number and the size of the tumors [4].

Insulin receptor substrates (IRSs) are involved in insulin signaling pathway [6]. IRS-2 plays an important role in glucose metabolism, tumor progression, and metastasis [7]. A host of studies [8-12] investigated the association between IRS-2 gene rs1805097 polymorphism and CRC risk, but with conflicting findings. These conflicting and inconclusive results may due to clinical heterogeneity, diverse ethnic populations, different tumor types, and small sample sizes. Therefore, we performed a comprehensive meta-analysis to clarify the possible association between IRS-2 gene rs 1805097 polymorphism and CRC risk.

\section{RESULTS}

\section{Characteristics of the included studies}

We yielded a total of 51 citations after initial search. 33 citations were removed after removing duplicates and screening the titles and abstracts. 18 citations were selected for further full text review. 13 citations were excluded: 1 investigated other polymorphisms; 5 were about other diseases; 2 were meta-analyses. Finally, 5 citations [8-12] containing 6 studies ( 4,333 cases and 5,333 controls) were included in this meta-analysis. Selection for eligible studies included in this meta-analysis was presented in Figure 1. The characteristics of included studies are summarized in Table 1. The Newcastle-Ottawa Scale (NOS) scores of all included studies ranged from 5 to 8 stars. All studies conformed to the Hardy-Weinberg equilibrium (HWE). 


\section{Meta-analysis of IRS-2 gene rs1805097 polymorphism}

As shown in Table 2, we detected an association between IRS-2 gene rs 1805097 polymorphism and CRC risk (AA+GA vs. GG: OR, 0.91; 95\% CI, 0.84-0.99, $P$ $=0.022$, Figure 2$)$. Stratification analysis by ethnicity indicated that rs 1805097 polymorphism was significantly associated with a decreased risk of CRC among Americans (AA+GA vs. GG: OR, 0.88 ; 95\% CI, 0.80-0.97, $P=0.007$, Figure 3), but not among other Caucasians. Stratification analysis of cancer type suggested that this polymorphism decreased the risk of colon cancer (AA+GA vs. GG: OR, 0.84 ; 95\% CI, 0.76-0.94, $P=0.002$, Figure 4). Regarding stratification analysis by source of control (SOC), no positive result was obtained in both population-based population and hospital-based population (Table 3 ).

We assessed sensitivity by omitting each study once at a time in every genetic model for rs 1805097 polymorphism. Our data indicated that the findings of this meta-analysis were stable and trustworthy (AA vs. GG+GA, Figure 5). Both Egger's and Begg's tests (A vs. G, Figure 6) revealed that there was no obvious publication bias for rs 1805097 polymorphism (data not shown).

\section{DISCUSSION}

In this current meta-analysis, we found that IRS2 gene rs1805097 polymorphism decreased the risk of CRC. Stratification analysis revealed that rs 1805097 polymorphism was associated with a decreased risk of CRC among Americans. In addition, stratification analysis of cancer type suggested that rs 1805097 polymorphism decreased the risk of colon cancer.

Insulin, a hormone, controls the energy homeostasis by functioning on target tissues. Insulin increases cell proliferation and decreases apoptosis [4, 13]. Many studies indicated that hyperinsulinemia and insulin resistance (IR) are involved in the etiology of CRC [14]. Hyperinsulinemia interacting with obesity was an important risk factor for CRC [4, 14]. Larsson et al. found a relationship between diabetes and increased risk of CRC [13]. Insulin-like growth factor (IGF), insulin-like growth factor binding proteins (IGFBPs), insulin and IRS play crucial roles in the initiation of cell growth and CRC proliferation $[15,16]$. IRS-2 mediates the major metabolic, proliferative, and antiapoptotic functions of the IGF1 [17, 18]. IRS-2 gene variants were reported to be involved in the modulation of IRS-1 or IRS-2 functions and could be relevant to colorectal tumorigenesis [19]. So far, a number

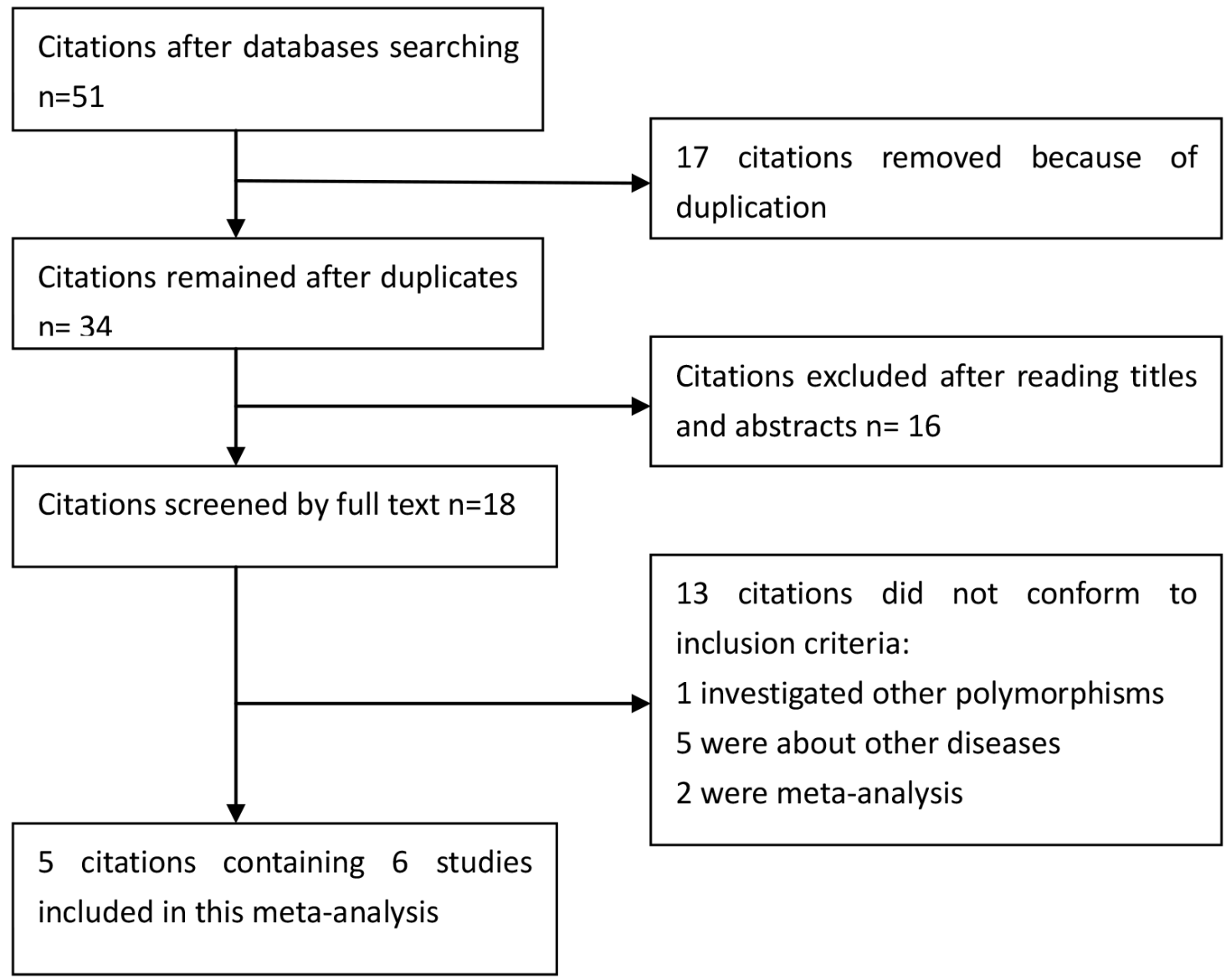

Figure 1: Selection for eligible publications included in this meta-analysis. 
Table 1: Characteristics of included studies

\begin{tabular}{lccccccccccccc}
\hline Author and year & Country & SOC & $\begin{array}{c}\text { Genotype } \\
\text { methods }\end{array}$ & Ethnicity & & Case & & & Control & HWE & NOS \\
\hline & & & & & GG & GA & AA & GG & GA & AA & \\
\hline Mahmoundi_2014 & Iran & HB & PCR & Caucasian & 109 & 118 & 34 & 139 & 153 & 47 & Y & 6 \\
Yukselogu_2014 & Turkey & HB & PCR-RFLP & Caucasian & 79 & 58 & 24 & 88 & 85 & 24 & Y & 7 & 72 \\
Pechivanis_2007 & Czech & HB & PCR & Caucasian & 211 & 277 & 81 & 268 & 309 & 106 & Y & 7 \\
Samowitz_2006 & USA & HB & PCR & American & 718 & 657 & 197 & 829 & 906 & 229 & Y & 8 \\
Slattery_2004a & USA & PB & PCR & American & 467 & 409 & 128 & 481 & 552 & 134 & Y & 6 \\
Slattery_2004b & USA & PB & PCR & American & 325 & 343 & 562 & 421 & 423 & 139 & Y & 6 \\
\hline
\end{tabular}

Abbreviations: SOC, source of control; PB, population-based controls; HB, hospital-based controls; HWE,

Hardy-Weinberg equilibrium; NOS, Newcastle-Ottawa Scale.

Table 2: Meta-analysis of association between IRS-2 rs1805097 polymorphism and colorectal cancer risk

\begin{tabular}{lccccc}
\hline Comparison & OR(95\%CI) & $\boldsymbol{P}$-value & $\begin{array}{c}\boldsymbol{P} \text { for } \\
\text { heterogeneity }\end{array}$ & $\mathbf{I}^{\mathbf{2}} \mathbf{( \% )}$ & Model \\
\hline A vs. G & $0.96(0.90,1.01)$ & 0.132 & 0.939 & 0 & Fixed \\
AA+GA vs. GG & $\mathbf{0 . 9 1 ( 0 . 8 4 , 0 . 9 9 )}$ & 0.022 & 0.260 & 23.2 & Fixed \\
AA vs. GG+GA & $1.02(0.91,1.15)$ & 0.721 & 0.695 & 0 & Fixed \\
AA vs. GG & $0.97(0.86,1.10)$ & 0.669 & 0.994 & 0 & Fixed \\
GA vs. GG & $0.91(0.79,1.05)$ & 0.189 & 0.055 & 53.7 & Random \\
\hline
\end{tabular}

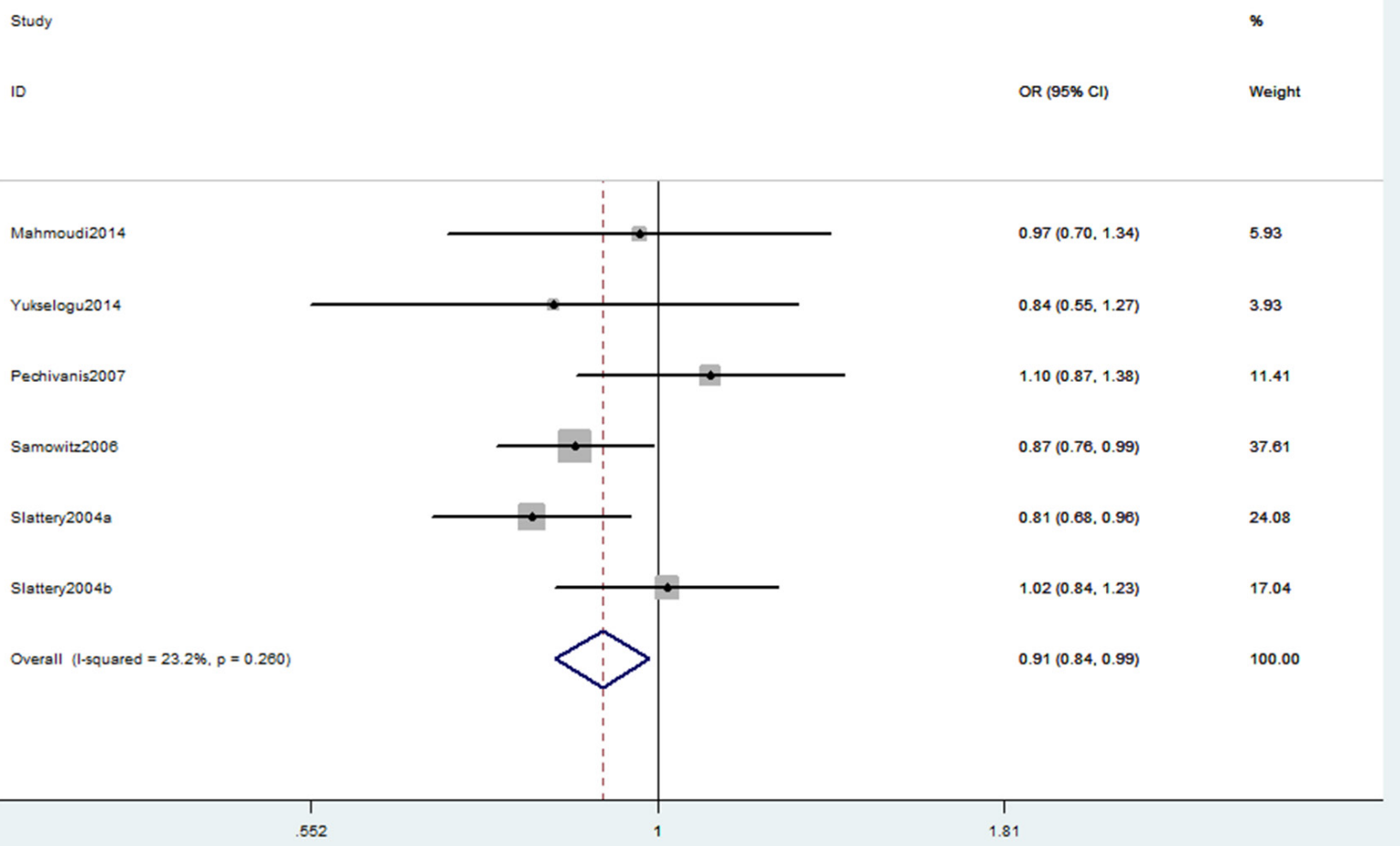

Figure 2: Forest plot shows odds ratio for the associations between rs1805097 polymorphism and CRC risk (AA+GA vs. GG). 


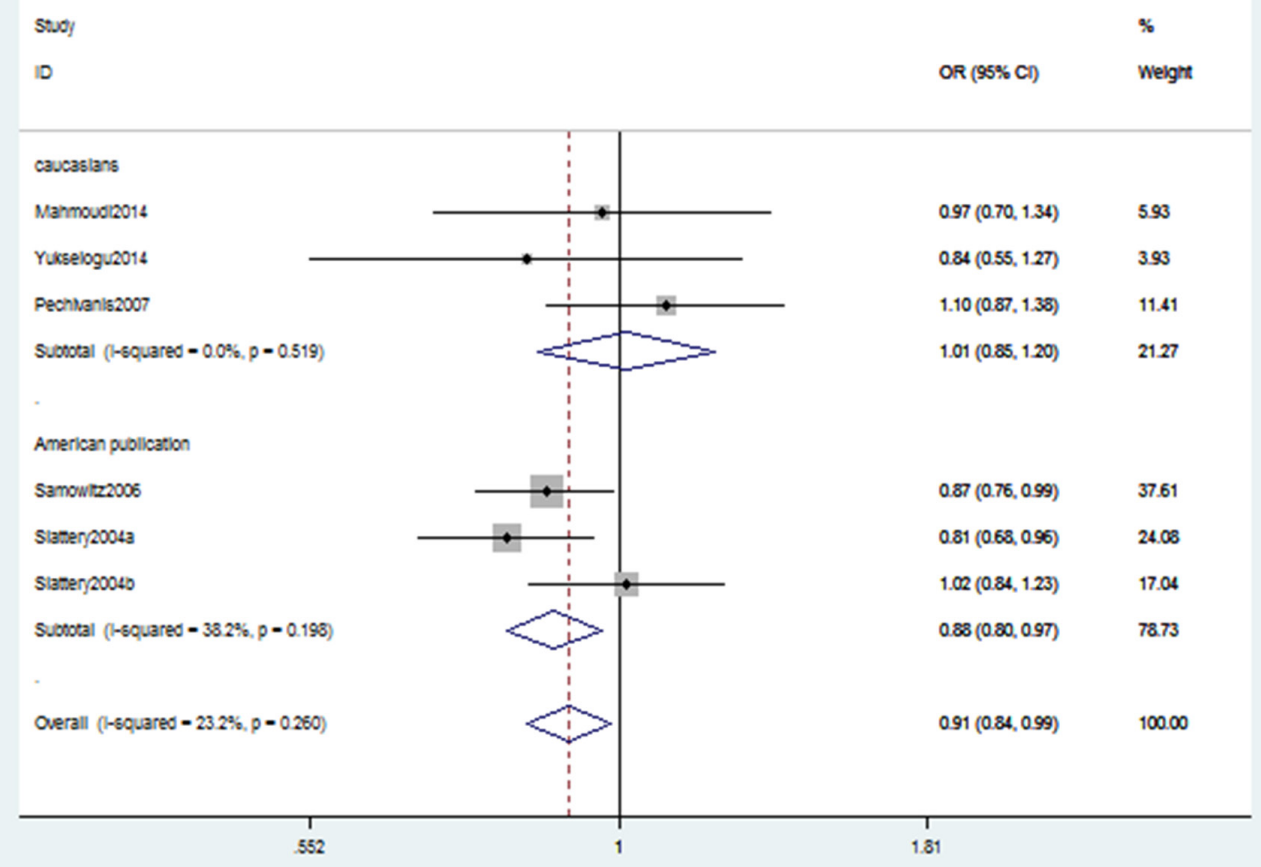

Figure 3: Stratification analyses by ethnicity shows odds ratio for the associations between rs1805097 polymorphism and CRC risk (AA+GA vs. GG).

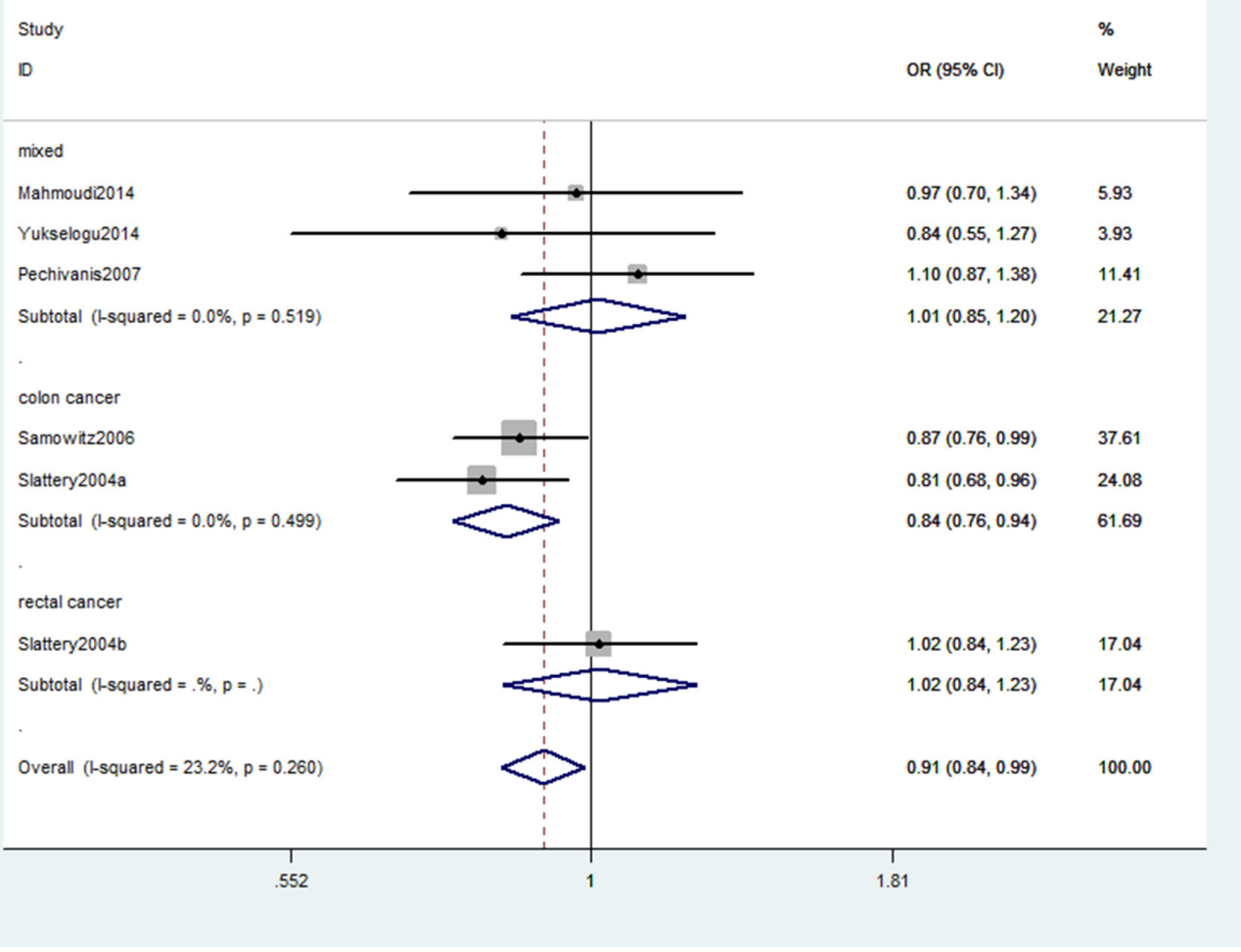

Figure 4: Stratification analyses of cancer type between rs1805097 polymorphism and CRC risk (AA+GA vs. GG). 
Table 3: Summary of the subgroup analyses in this meta-analysis

\begin{tabular}{|c|c|c|c|c|c|c|}
\hline Comparison & Category & Category & Studies & OR $(95 \%$ CI $)$ & $P$-value & $\begin{array}{c}P \text { for } \\
\text { heterogeneity }\end{array}$ \\
\hline \multirow[t]{7}{*}{ A vs. G } & \multirow[t]{2}{*}{ Ethnicity } & Caucasians & 3 & $1.00(0.88,1.13)$ & 0.943 & 0.913 \\
\hline & & Americans & 3 & $0.94(0.88,1.01)$ & 0.093 & 0.939 \\
\hline & \multirow[t]{3}{*}{ Cancer type } & mixed & 3 & $1.00(0.88,1.13)$ & 0.943 & 0.913 \\
\hline & & Colon cancer & 2 & $0.93(0.86,1.01)$ & 0.078 & 0.696 \\
\hline & & Rectal cancer & 1 & $0.98(0.85,1.13)$ & 0.772 & $<0.001$ \\
\hline & \multirow[t]{2}{*}{ SOC } & HB & 4 & $0.96(0.89-1.04)$ & 0.350 & 0.892 \\
\hline & & $\mathrm{PB}$ & 2 & $0.94(0.86-1.04)$ & 0.218 & 0.472 \\
\hline \multirow[t]{7}{*}{$\mathrm{AA}+\mathrm{GA}$ vs. GG } & \multirow[t]{2}{*}{ Ethnicity } & Caucasians & 3 & $1.01(0.85,1.20)$ & 0.884 & 0.519 \\
\hline & & Americans & 3 & $0.88(0.80,0.97)$ & 0.007 & 0.198 \\
\hline & \multirow[t]{3}{*}{ Cancer type } & mixed & 3 & $1.01(0.85,1.20)$ & 0.884 & 0.519 \\
\hline & & Colon cancer & 2 & $0.84(0.76,0.94)$ & 0.002 & 0.499 \\
\hline & & Rectal cancer & 1 & $1.02(0.84,1.23)$ & 0.867 & $<0.001$ \\
\hline & \multirow[t]{2}{*}{$\mathrm{SOC}$} & HB & 4 & $0.92(0.83,1.02)$ & 0.125 & 0.358 \\
\hline & & PB & 2 & $0.89(0.79,1.01)$ & 0.082 & 0.076 \\
\hline \multirow[t]{7}{*}{ AA vs.GA+ GG } & \multirow[t]{2}{*}{ Ethnicity } & Caucasians & 3 & $0.96(0.75,1.22)$ & 0.732 & 0.625 \\
\hline & & Americans & 3 & $1.04(0.91,1.20)$ & 0.541 & 0.422 \\
\hline & \multirow[t]{3}{*}{ Cancer type } & mixed & 3 & $0.96(0.75,1.22)$ & 0.732 & 0.625 \\
\hline & & Colon cancer & 2 & $1.10(0.94,1.29)$ & 0.238 & 0.825 \\
\hline & & Rectal cancer & 1 & $0.89(0.67,1.18)$ & 0.414 & $<0.001$ \\
\hline & \multirow[t]{2}{*}{$\mathrm{SOC}$} & HB & 4 & $1.03(0.88,1.20)$ & 0.704 & 0.674 \\
\hline & & $\mathrm{PB}$ & 2 & $1.01(0.84,1.22)$ & 0.920 & 0.225 \\
\hline \multirow[t]{7}{*}{ AA vs.GG } & \multirow[t]{2}{*}{ Ethnicity } & Caucasians & 3 & $0.98(0.76,1.27)$ & 0.875 & 0.900 \\
\hline & & Americans & 3 & $0.97(0.84,1.12)$ & 0.687 & 0.898 \\
\hline & \multirow[t]{3}{*}{ Cancer type } & mixed & 3 & $0.98(0.76,1.27)$ & 0.875 & 0.900 \\
\hline & & Colon cancer & 2 & $0.99(0.84,1.17)$ & 0.904 & 0.957 \\
\hline & & Rectal cancer & 1 & $0.91(0.68,1.23)$ & 0.549 & $<0.001$ \\
\hline & \multirow[t]{2}{*}{$\mathrm{SOC}$} & HB & 4 & $0.99(0.84,1.17)$ & 0.882 & 0.975 \\
\hline & & PB & 2 & $0.95(0.78,1.16)$ & 0.662 & 0.718 \\
\hline \multirow[t]{7}{*}{ GA vs.GG } & \multirow[t]{2}{*}{ Ethnicity } & Caucasians & 3 & $1.01(0.82,1.24)$ & 0.929 & 0.292 \\
\hline & & Americans & 3 & $0.91(0.79,1.05)$ & 0.099 & 0.062 \\
\hline & \multirow[t]{3}{*}{ Cancer type } & mixed & 3 & $1.01(0.82,1.24)$ & 0.929 & 0.292 \\
\hline & & Colon cancer & 2 & $0.81(0.72,0.90)$ & $<0.001$ & 0.428 \\
\hline & & Rectal cancer & 1 & $1.05(0.86,1.29)$ & 0.635 & $<0.001$ \\
\hline & \multirow[t]{2}{*}{$\mathrm{SOC}$} & $\mathrm{HB}$ & 4 & $0.93(0.78,1.11)$ & 0.404 & 0.145 \\
\hline & & $\mathrm{PB}$ & 2 & $0.89(0.65,1.22)$ & 0.475 & 0.021 \\
\hline
\end{tabular}

Abbreviations: SOC, source of control; PB, population-based controls; HB, hospital-based controls. 


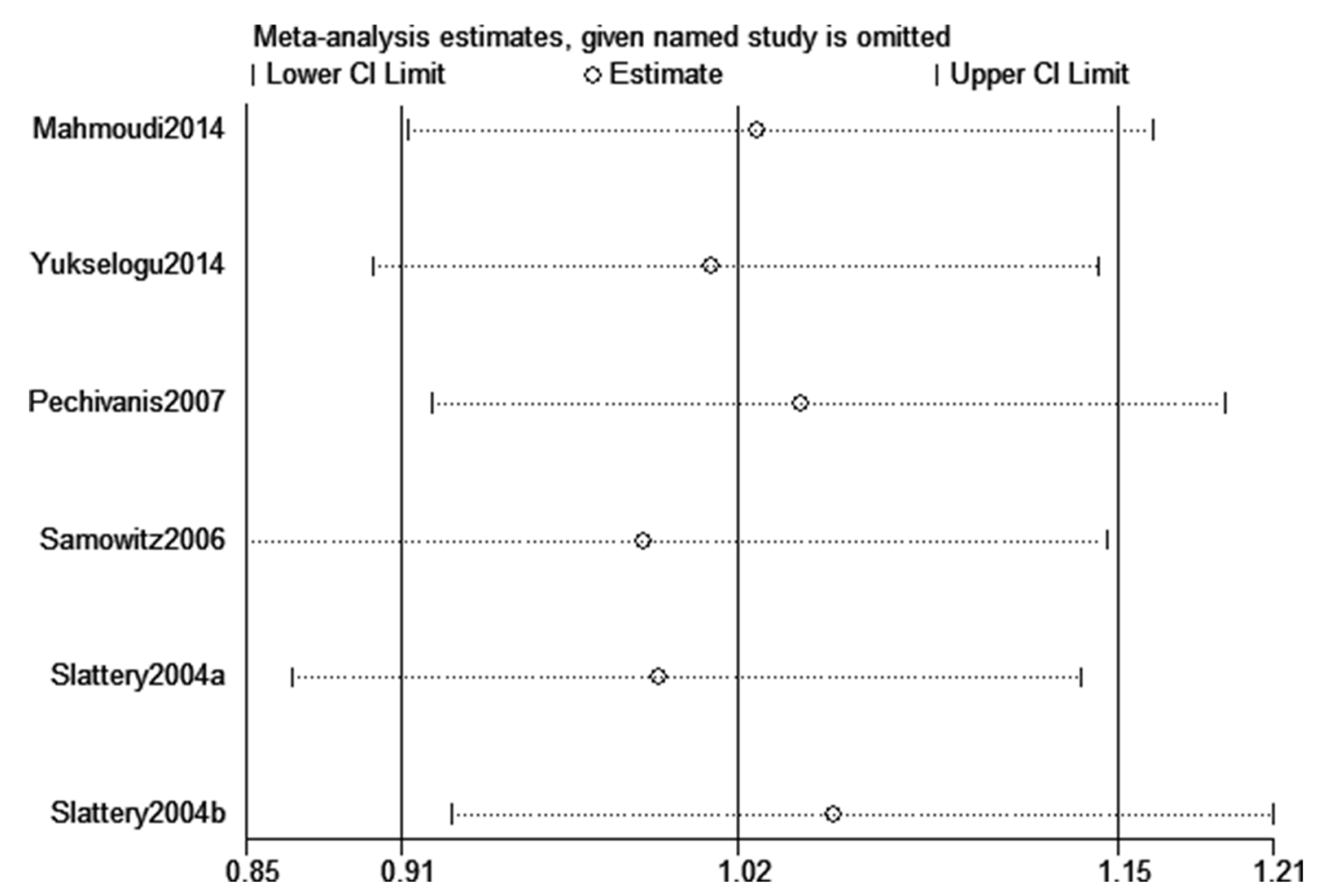

Figure 5: Sensitivity analysis about rs1805097 polymorphism and CRC risk (AA vs. GG+GA).

\section{Begg's funnel plot with pseudo 95\% confidence limits}

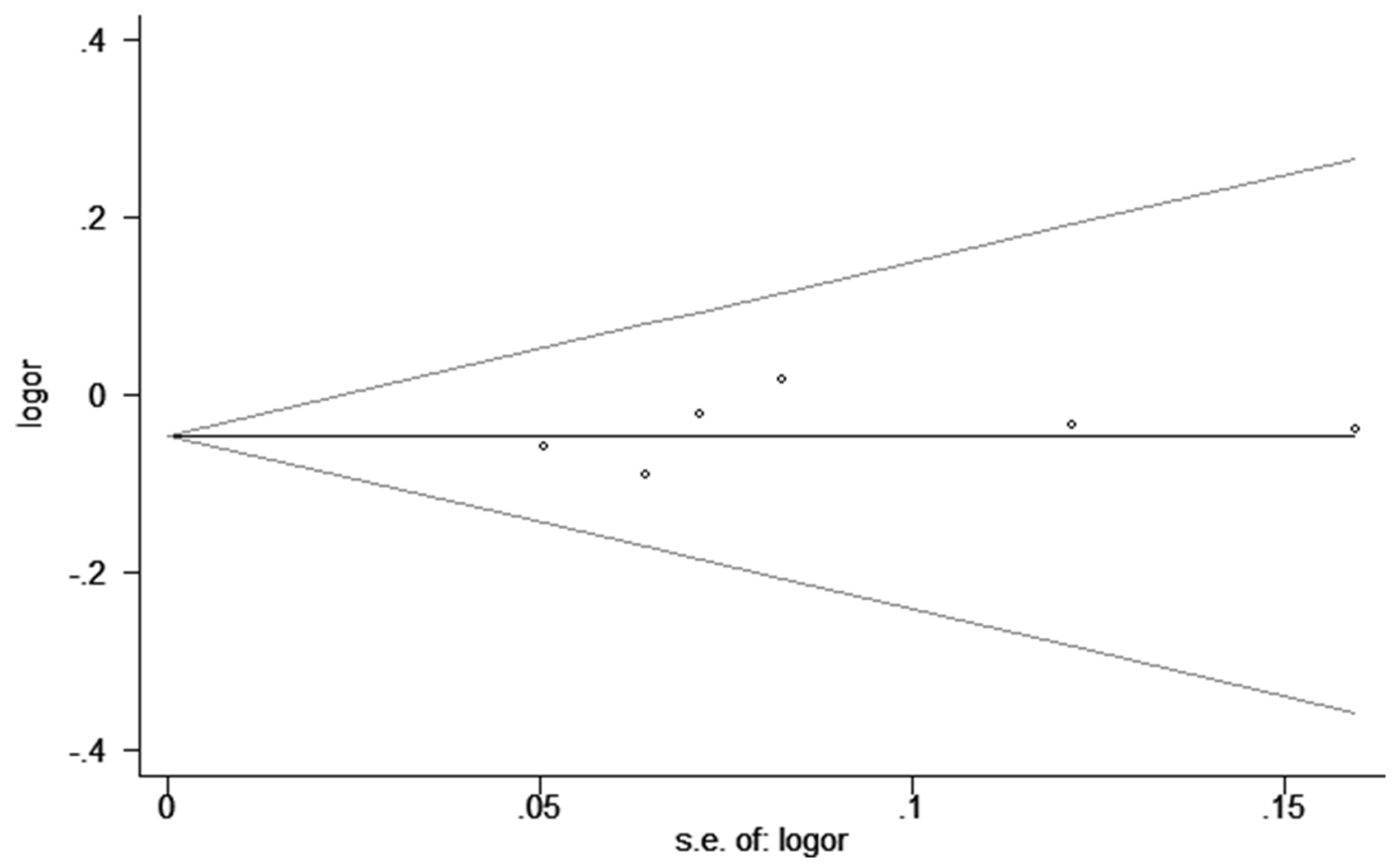

Figure 6: Begg's tests for rs1805097 polymorphism and CRC risk (A vs. G). 
of studies [8-12] investigated the association between IRS-2 gene rs1805097 polymorphism and CRC risk. However, these studies yield contradictory results. Thus, we conducted this current meta-analysis.

Previous meta-analysis by $\mathrm{Hu}$ et al. indicated that IRS-2 rs1805097 polymorphism was not associated with CRC risk [20]. They only included 4 studies. To date, two studies $[9,11]$ have been reported in recent years since the meta-analysis [20]. In analysis of all included studies, our meta-analysis found that rs1805097 polymorphism was associated with decreased CRC risk. We believed that $\mathrm{Hu}$ et al. falsely extracted the genotype numbers of cases and controls from an American study [8]. Actually, the genotype numbers of this study were as following: colon cancers $(\mathrm{GG}=467, \mathrm{GA}=409, \mathrm{AA}=128)$, controls $(\mathrm{GG}=481$, $\mathrm{GA}=552, \mathrm{AA}=134)$; rectal cancers $(\mathrm{GG}=325, \mathrm{GA}=343$, $\mathrm{AA}=98)$, controls $(\mathrm{GG}=421, \mathrm{GA}=423, \mathrm{AA}=139)$. In addition, the above false data explained the reason why the HWE value in this American study was wrong [8]. According to our data, the study [8] by Slattery et al. conformed to HWE. We also conducted stratification analysis of cancer type, which was not performed by Hu et al. [20]. Our data suggested that rs1805097 polymorphism was associated with a decreased risk of colon cancer.

We believe our meta-analysis more robust than previous meta-analysis by $\mathrm{Hu}$ et al. [20]. First, we included 2 extra studies and the sample size of this meta-analysis was larger than previous meta-analysis. Second, sensitivity analysis indicated that our data about rs1805097 polymorphism were trustworthy and stable. Third, the power analysis indicated that this meta-analysis had a power of $96.9 \%$ to detect the effect of rs 1805097 polymorphism on CRC risk with an OR of 0.91 .

Several potential limitations should be addressed in this meta-analysis. First, due to limited data, we could not investigate the association between CRC and other potential factors, such as age and sex. Second, our results were based on unadjusted estimates for confounding factors, which might have affected the final findings. Third, we could not assess potential gene-gene and geneenvironment interactions because of the lack of relevant data. Fourth, the sample size of this meta-analysis is not very large, and the number of included studies is small. Fifth, the findings of the stratified analyses should be interpreted with caution because of limited sample sizes.

In conclusion, this meta-analysis indicates that IRS-2 gene rs1805097 polymorphism decreased the risk of CRC. Further studies are necessary to validate whether rs1805097 polymorphism contributes to CRC susceptibility in other ethnic groups.

\section{MATERIALS AND METHODS}

\section{Literature search and inclusion criteria}

We systematically searched the PubMed and Embase to identify studies through August 19, 2016. The following search terms were used: "cancer," "carcinoma," "neoplasm," "tumor," "Insulin Receptor Substrate 2," "IRS-2," and "IRS 2". No restrictions were placed on the literature search. Reference lists were identified by hand screening. The identified studies conformed to the following criteria: (1) studies that evaluated the association between IRS-2 gene rs1805097 polymorphism and CRC risk, (2) study provided sufficient data to calculate the odds ratios (ORs) and 95\% confidence intervals (CIs), (3) case-control study.

\section{Data extraction and quality assessment}

Relevant information was carefully extracted from all eligible studies. The extracted information from all eligible studies including: name of first author, publication year, country of origin, ethnicity, genotype methods and genotype numbers of cases and controls. Two authors independently performed the extraction of data and assessed the study quality based on the NOS [21]. All disagreements were discussed and resolved with consensus.

\section{Statistical analyses}

All statistical analyses were performed using the Stata 11.0 software (StataCorp, College Station, TX, USA). ORs and 95\%CIs were used to assess the strength of association between IRS-2 gene rs1805097 polymorphism and CRC risk. Stratification analyses were carried out by ethnicity, SOC and cancer type. When a $\mathrm{Q}$ test indicated $P<0.1$ or $\mathrm{I}^{2}>50 \%$ indicated heterogeneity across studies, a random-effect model was used. Otherwise, the fixed-effects model was applied [22]. Allele model, dominant model, recessive model, homozygous model, and heterozygous model were used in this meta-analysis. We performed leave-one-out sensitivity analysis to evaluate the stability of the overall results. We assessed the departure from the HWE in the controls using Pearson's $\chi 2$ test. Potential publication bias was assessed by Begger's and Egger's linear regression test [23]; $P<$ 0.05 was considered to indicate statistically significant. The power of this meta-analysis was calculated with a significant value of 0.05 [24].

\section{Abbreviations}

CRC, colorectal cancer; IRS-2, insulin receptor substrate-2; IRS, insulin receptor substrates; IGF, insulinlike growth factor; IGFBP, insulin-like growth factor binding protein; IR, insulin resistance; SOC, source of control; CI, confidence interval; OR, odds ratio; NOS, Newcastle-Ottawa Scale; HWE, Hardy-Weinberg equilibrium; SNP, single nucleotide polymorphism

\section{CONFLICTS OF INTEREST}

The authors declare no conflicts of interest. 


\section{REFERENCES}

1. Ferlay J, Shin HR, Bray F, Forman D, Mathers C, Parkin DM. Estimates of worldwide burden of cancer in 2008: GLOBOCAN 2008. International journal of cancer. 2010; 127:2893-2917.

2. de la Chapelle A. Genetic predisposition to colorectal cancer. Nature reviews Cancer. 2004; 4:769-780.

3. Sandhu MS, Dunger DB, Giovannucci EL. Insulin, insulinlike growth factor-I (IGF-I), IGF binding proteins, their biologic interactions, and colorectal cancer. Journal of the National Cancer Institute. 2002; 94:972-980.

4. Giovannucci E. Insulin, insulin-like growth factors and colon cancer: a review of the evidence. The Journal of nutrition. 2001; 131:3109S-3120S.

5. Keku TO, Lund PK, Galanko J, Simmons JG, Woosley JT, Sandler RS. Insulin resistance, apoptosis, and colorectal adenoma risk. Cancer epidemiology, biomarkers \& prevention. 2005; 14:2076-2081.

6. Withers DJ. Insulin receptor substrate proteins and neuroendocrine function. Biochemical Society transactions. 2001; 29:525-529.

7. Reuveni H, Flashner-Abramson E, Steiner L, Makedonski K, Song R, Shir A, Herlyn M, Bar-Eli M, Levitzki A. Therapeutic destruction of insulin receptor substrates for cancer treatment. Cancer research. 2013; 73:4383-4394.

8. Slattery ML, Samowitz W, Curtin K, Ma KN, Hoffman M, Caan B, Neuhausen S. Associations among IRS1, IRS2, IGF1, and IGFBP3 genetic polymorphisms and colorectal cancer. Cancer epidemiology, biomarkers \& prevention. 2004; 13:1206-1214.

9. Mahmoudi T, Majidzadeh AK, Karimi K, Karimi N, Farahani H, Dabiri R, Nobakht H, Dolatmoradi H, Arkani $\mathrm{M}$, Zali MR. An exon variant in insulin receptor gene is associated with susceptibility to colorectal cancer in women. Tumour biology. 2015; 36:3709-3715.

10. Pechlivanis S, Pardini B, Bermejo JL, Wagner K, Naccarati A, Vodickova L, Novotny J, Hemminki K, Vodicka P, Forsti A. Insulin pathway related genes and risk of colorectal cancer: INSR promoter polymorphism shows a protective effect. Endocrine-related cancer. 2007; 14:733-740.

11. Yukseloglu EH, Celik SK, Kucuk MU, Yalin E, Ozkal SS, Ates C, Berkoz M, Yalin S, Ates NA. IRS-2 G1057D polymorphism in Turkish patients with colorectal cancer. Przeglad gastroenterologiczny. 2014; 9:88-92.

12. Samowitz WS, Wolff RK, Ma KN, Andersen K, Caan B, Slattery ML. Polymorphisms in insulin-related genes predispose to specific KRAS2 and TP53 mutations in colon cancer. Mutation research. 2006; 595:117-124.

13. Larsson SC, Orsini N, Wolk A. Diabetes mellitus and risk of colorectal cancer: a meta-analysis. Journal of the National Cancer Institute. 2005; 97:1679-1687.

14. Limburg PJ, Stolzenberg-Solomon RZ, Vierkant RA, Roberts K, Sellers TA, Taylor PR, Virtamo J, Cerhan JR, Albanes D. Insulin, glucose, insulin resistance, and incident colorectal cancer in male smokers. Clinical gastroenterology and hepatology. 2006; 4:1514-1521.

15. Furstenberger G, Senn HJ. Insulin-like growth factors and cancer. The Lancet Oncology. 2002; 3:298-302.

16. Jackson JG, Zhang X, Yoneda T, Yee D. Regulation of breast cancer cell motility by insulin receptor substrate-2 (IRS-2) in metastatic variants of human breast cancer cell lines. Oncogene. 2001; 20:7318-7325.

17. Schubert M, Brazil DP, Burks DJ, Kushner JA, Ye J, Flint CL, Farhang-Fallah J, Dikkes P, Warot XM, Rio C, Corfas $\mathrm{G}$, White MF. Insulin receptor substrate-2 deficiency impairs brain growth and promotes tau phosphorylation. The Journal of neuroscience. 2003; 23:7084-7092.

18. Dearth RK, Cui X, Kim HJ, Hadsell DL, Lee AV. Oncogenic transformation by the signaling adaptor proteins insulin receptor substrate (IRS)-1 and IRS-2. Cell cycle. 2007; 6:705-713.

19. Esposito DL, Verginelli F, Toracchio S, Mammarella S, De Lellis L, Vanni C, Russo A, Mariani-Costantini R, Cama A. Novel insulin receptor substrate 1 and 2 variants in breast and colorectal cancer. Oncology reports. 2013; 30:1553-1560.

20. Hu Y, Zhou M, Zhang K, Kong X, Hu X, Li K, Liu L. Lack of association between insulin receptor substrate 2 rs1805097 polymorphism and the risk of colorectal and breast cancer: a meta-analysis. PloS one. 2014; 9:e86911.

21. Stang A. Critical evaluation of the Newcastle-Ottawa scale for the assessment of the quality of nonrandomized studies in meta-analyses. European journal of epidemiology. 2010; 25:603-605.

22. Higgins JP, Thompson SG. Quantifying heterogeneity in a meta-analysis. Statistics in medicine. 2002; 21:1539-1558.

23. Peters JL, Sutton AJ, Jones DR, Abrams KR, Rushton L. Comparison of two methods to detect publication bias in meta-analysis. Jama. 2006; 295:676-680.

24. Hedges LV, Pigott TD. The power of statistical tests in meta-analysis. Psychological methods. 2001; 6:203-217. 